\title{
Análise espectral e temporal da cultura do café em imagens Landsat
}

\author{
Mauricio Alves Moreira ${ }^{(1)}$, Marcos Adami(2) e Bernardo Friedrich Theodor Rudorff ${ }^{(1)}$
}

\begin{abstract}
(1)Instituto Nacional de Pesquisas Espaciais, Av. dos Astronautas, 1758, CEP 12227-010 São José dos Campos, SP. E-mail: mauricio@ltid.inpe.br; bernardo@Itid.inpe.br (2)Secretaria de Estado da Agricultura e do Abastecimento do Paraná, Av. Minas Gerais, 1.351, CEP 86300-000 Cornélio Procópio, PR. E-mail: adami@pr.gov.br
\end{abstract}

\begin{abstract}
Resumo - A definição da resposta espectral da cultura do café é uma das etapas na identificação de lavouras cafeeiras em imagens de satélites de sensoriamento remoto, para fins de mapeamento e estimativa de área plantada. O objetivo deste trabalho foi avaliar o potencial das imagens adquiridas pelos satélites da série Landsat, no mapeamento da cultura do café para a previsão de safras. Foi feita uma análise temporal do comportamento espectral de lavouras de café-formação e café-produção por meio de imagens livres de nuvens adquiridas nos anos de 1999 e 2001. Também foi analisado o comportamento espectral das classes pastagem e mata, que compõem os alvos de maior ocupação na área de estudo. As imagens do período seco foram mais eficientes no mapeamento de lavouras de café-formação e café-produção. As imagens da banda 4 dos dois sensores apresentaram melhor diferenciação espectral entre café e os demais alvos da cena. A reflectância do café-produção apresentou grande variabilidade entre lavouras, que pode ser atribuída à idade, espaçamento de plantas, cultivar, indicando a necessidade de trabalho em campo para a correta identificação das lavouras de café nas imagens Landsat.
\end{abstract}

Termos para indexação: Coffea arabica, sensoriamento remoto, geoprocessamento, previsão de safra.

\section{Spectral and temporal behavior analysis of coffee crop in Landsat images}

\begin{abstract}
The definition of the spectral response of coffee crop is one of the steps to identify coffee fields in remote sensing images in order to map and estimate planted area. The objective of this work was to analyze the potential of the images acquired by the Landsat series satellites, for coffee crop mapping and forecast. A temporal analysis of the spectral behavior of coffee crop fields under development and under active production was performed through cloud free images acquired in the years of 1999 and 2001. The spectral behavior of pasture and forest was also analyzed due to their relevance in the study area. The results showed that images acquired during the dry season were more efficient to map coffee crop at early development and under production. Band 4 (near infrared) of both sensors (TM and $\mathrm{ETM}^{+}$) presented best performance for spectral differentiation between coffee crop and other scene targets. The analysis of the reflectance values for active producing coffee crop showed a high spectral variability which may be attributed to age, plants spacing, cultivar, indicating a need for field work for the identification of coffee crop in Landsat scenes.
\end{abstract}

Index terms: Coffea arabica, remote sensing, geoprocessing, crop forecast.

\section{Introdução}

A cultura do café destaca-se historicamente no desenvolvimento do País. As características do cultivo, ainda hoje, são altamente depedentes do serviço braçal, o que lhe atribui uma importante função social, por gerar empregos diretos no setor rural (Mello, 2001). Além do emprego direto, o agronegócio do café proporciona, no setor urbano, emprego indireto nas fases de beneficiamento e comercialização do produto.
Conforme Zambolim (2001), o sucesso na cafeicultura ocorre em virtude de vários fatores, destacando-se a redução dos custos de produção, o aumento na produtividade, a busca constante de qualidade, a preservação do meio ambiente, a conquista de novos mercados consumidores e a definição de políticas agrícola para o setor cafeeiro. Quanto à definição de políticas agrícolas para o setor cafeeiro, um dos aspectos que se deve considerar é o estabelecimento de um sistema de previsão de safra eficiente e objetivo que atenda às necessida- 
des de planejamento e de comercialização, para evitar que o agronegócio do café fique à mercê dos especuladores internos e externos. Pino (2001) ressalta a importância de aprimorar os atuais métodos subjetivos de estimativa da produção mediante a inclusão de novas tecnologias, como as imagens de satélites de sensoriamento remoto e os Sistemas de Informação Geográfica (SIGs).

O uso operacional de imagens de satélites de sensoriamento remoto com a finalidade de estimar a área plantada com café requer estudos suplementares que definam métodos apropriados. Os resultados dos primeiros estudos com imagens do sensor MSS (Multispectral Scanner Subsytem) do Landsat, na identificação e estimativa de áreas com café, não permitiram adequada discriminação dos cafezais em relação aos alvos adjacentes (Veloso, 1974; Veloso \& Souza, 1976, 1978). Posteriormente, Tardin et al. (1992) mostraram que esta cultura poderia ser mapeada pelas imagens do sensor TM (Thematic Mapper) do Landsat-5. Todavia, este trabalho não explorou o aspecto multitemporal das imagens e não definiu épocas mais favoráveis na identificação das lavouras de café e sua discriminação dos demais alvos da cena. Características da lavoura de café, como espaçamento, idade, cultivar, face do relevo e tratos culturais, podem ter influência relevante no comportamento espectral e também não foram consideradas nos trabalhos anteriormente referidos.

O objetivo deste trabalho foi avaliar o potencial das imagens adquiridas pelos satélites da série Landsat, no mapeamento da cultura do café para a previsão de safras.

\section{Material e Métodos}

Foram selecionadas lavouras cafeeiras comerciais, localizadas no município de Aguanil, centro-sul do Estado de Minas Gerais, com coordenadas geográficas centrais de $20^{\circ} 58^{\prime} \mathrm{S}$ e $45^{\circ} 25^{\prime} \mathrm{W}$.

As razões que levaram à escolha desse município e das datas das imagens para o estudo do comportamento espectral da cultura do café foram o amplo conhecimento da área de estudo, a grande diversidade de sistema de plantio e de manejo da cultura, o cultivo em diferentes condições de relevo e a disponibilidade de imagens do Landsat livre de nuvens nos anos de 1999 e 2001.

Os solos da área são de baixa fertilidade, com predo- mínio de Latossolos (Embrapa, 1999). Quanto ao relevo, destacam-se o suave ondulado e o acidentado. De modo geral, o café é mais abundante no relevo suave ondulado, tanto em número de lavouras quanto em área plantada. Nas partes mais acidentadas, encontramse lavouras de café no topo ou no primeiro terço do morro. Nessa situação, as lavouras são quase todas circundadas por matas ou cerrado, enquanto, na parte em que o relevo é suave ondulado, as lavouras estão quase sempre rodeadas por pastagens naturais ou artificiais e lavouras de verão.

$\mathrm{Na}$ análise temporal do comportamento espectral das lavouras de café, a primeira etapa foi gerar o banco de dados contendo imagens no formato digital das bandas 3, 4 e 5 dos sensores TM e ETM+, para sete datas de passagem dos satélites Landsat-5 e 7, correspondentes à órbita 219 e ao ponto 74 (Tabela 1).

Nas imagens inseridas no banco de dados, aplicaramse os procedimentos de pré-processamento, ou seja, realce de imagens, registro e recorte da área de estudo. A fim de diminuir a interferência dos efeitos atmosféricos nas imagens, obtidas em datas diferentes, aplicouse o procedimento de retificação, que consiste na utilização de uma imagem com boa qualidade radiométrica, adquirida sob condições de atmosfera limpa, para corrigir os efeitos atmosféricos das demais imagens (Hall et al., 1991). A imagem que apresentou melhor qualidade radiométrica foi a de 3 de setembro de 1999. Todo procedimento de retificação foi realizado no aplicativo PCI (PCI Remote Sensing Corp., 1997) (Figura 1), cujos passos são descritos a seguir: a) criação dos canais: são planos de informações criados no PCI para armazenar as imagens de cada data de passagem do satélite; b) imagem reflectância: é a transformação das imagens de nível de cinza para reflectância, usando o programa Reflet.mod do aplicativo PCI; c) imagens verdor e brilho: são geradas por meio do programa Grbr.mod do aplicativo PCI, a partir das imagens reflectância das bandas 3, 4 e 5 (Kauth \& Thomas, 1976; Hall et al.,

Tabela 1. Informação das imagens orbitais.

\begin{tabular}{lcc}
\hline Satélite & Órbita/ponto & Data \\
\hline Landsat-5 & $219 / 74$ & $10 / 08 / 1999$ \\
Landsat-7 & $219 / 74$ & $03 / 09 / 1999$ \\
Landsat-5 & $219 / 74$ & $27 / 09 / 1999$ \\
\hline Landsat-7 & $219 / 74$ & $17 / 04 / 2001$ \\
Landsat-7 & $219 / 74$ & $19 / 05 / 2001$ \\
Landsat-7 & $219 / 74$ & $07 / 08 / 2001$ \\
Landsat-7 & $219 / 74$ & $01 / 11 / 2001$ \\
\hline
\end{tabular}




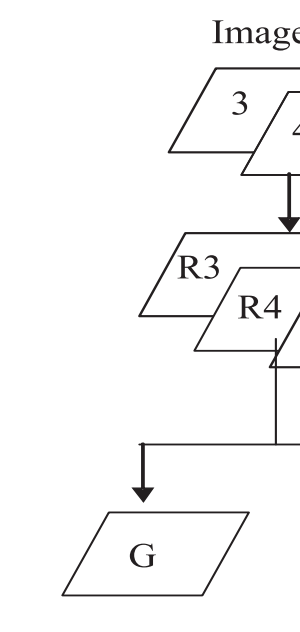

magem base
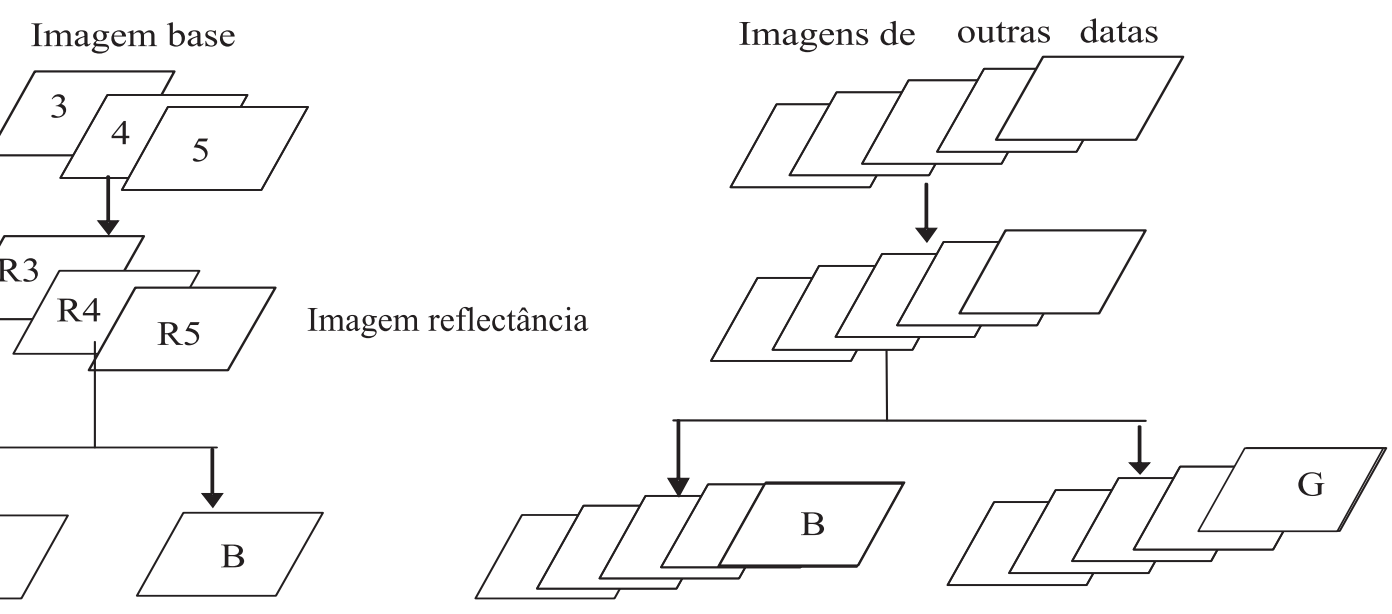

Imagens verdor (G) e brilho (B)

Análise do diagrama de dispersão das imagens G e B

da data base e das datas a serem restituídas.

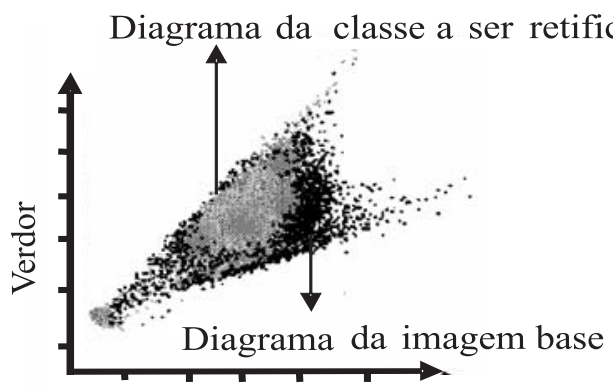

Brilho

Cálculo das médias de reflectância dos pontos claros e escuros nas imagens reflectância das bandas 3, 4 e 5 da data base e nas imagens a serem restituídas

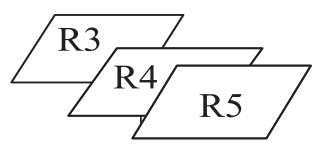

Data base

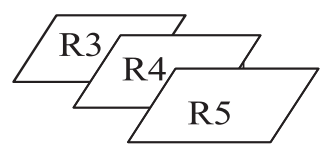

Outras datas

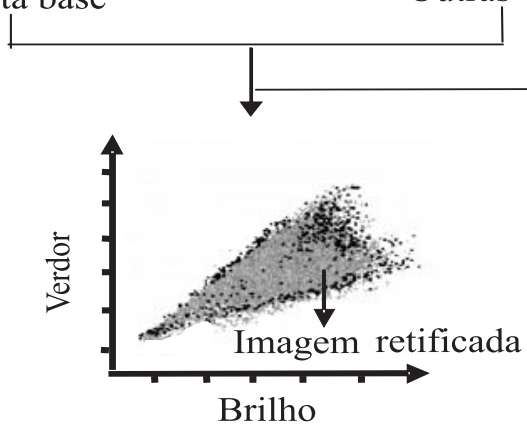

Figura 1. Fluxograma ilustrativo da sequência metodológica para retificação radiométrica das imagens multitemporais dos sensores TM e ETM+ ${ }^{+}$do Landsat-5 e 7, respectivamente. 
1991); d) criação de máscaras: consiste em determinar sobre as imagens verdor e brilho amostras para extrair informações espectrais, que representam as classes água (escuro) e solo exposto (claro). Para facilitar a escolha das amostras tanto na imagem base quanto na imagem a ser retificada, utiliza-se o gráfico de dispersão (eixo Y - valores de verdor e eixo X - valores de brilho); e) médias de reflectância: procedimento adotado para determinar as médias dos pontos escuros e claros para todas as datas, nas imagens verdor e brilho; f) correção das médias: consiste em corrigir as médias das imagens (verdor e brilho) a serem retificadas, obtidas na etapa anterior, em função da média da imagem base obtida em 3/9/1999; g) análise dos resultados: consiste em sobrepor o diagrama da imagem retificada sobre o diagrama de dispersão da imagem base, para verificar a qualidade da retificação. Se a dispersão dos dados retificados estiver de acordo com a dispersão da imagem base o resultado é considerado satisfatório, caso contrário, reiniciase o procedimento a partir da etapa (d). Uma vez concluído este procedimento no aplicativo PCI, as imagens foram exportadas para o aplicativo SPRING (Instituto Nacional de Pesquisas Espaciais, 2003).

Com uma imagem em papel de 10 de setembro de 2001, na escala de 1:50.000, foi realizado um trabalho no campo, no mês de janeiro de 2002, para identificar todas as áreas de café no município. Após esse levantamento, foram selecionadas 62 lavouras de café em formação e em produção, quanto à idade e ao espaçamento. Nesta etapa, foram levantadas informações sobre 31 lavouras de café em formação com idade menor do que cinco anos em 2001, e maior do que um ano e meio em 1999; e 31 lavouras de café em produção com idade acima de cinco anos em 1999. A informação obtida no campo foi registrada na imagem em papel e num questionário de campo, a fim de delimitar os polígonos das lavouras de café nas imagens digitais, para posterior extração dos valores de reflectância de cada lavoura nas imagens das bandas 3, 4 e 5. Além das áreas de café, foram extraídas informações de reflectância de outros alvos de ocupação do solo, como pastagem e mata, que são os alvos que predominam na área e podem ser confundidos com o café nas imagens do satélite.

A mata foi considerada de modo generalizado, ou seja, mata reserva, cerrado e mata galeria. A pastagem predominante na região é constituída pela braquiária (Brachiaria decumbens). Entretanto, nas regiões de relevo mais acidentado do município é possível encontrar pastagem natural. Todas estas informações foram inseridas num banco de dados relacional no aplicativo SPRING.

A análise de variância e o teste de Tukey a 5\% de probabilidade, em amostras de diferentes tamanhos, foram aplicados nos valores médios de reflectância obtidos para cada polígono dos alvos: café-produção, caféformação, pastagem e mata. Os resultados também foram expressos sob a forma de gráficos, de modo a analisar a variabilidade espectral e temporal de cada lavoura de café (formação e produção) e também as classes de mata e pastagem.

Foi realizada também a análise da variabilidade espectral de cada lavoura de café em produção, selecionada nas imagens adquiridas em agosto de 1999 e de 2001.

\section{Resultados e Discussão}

Com os valores médios de reflectância, obtidos nas bandas 3, 4 e 5, fez-se a análise estatística em relação aos anos de 1999 e 2001 (Tabelas 2 e 3). A análise de variância indicou haver diferença significativa entre os temas analisados nos dois anos.

Em relação à banda 4, para o ano de 1999, as classes café-formação e café-produção não diferiram entre si, mas diferiram das classes mata e pastagem em todas as datas (Tabela 2). Esse resultado indica que o uso de imagens obtidas nessa banda espectral é fundamental para diferenciar café de mata e pastagem. Veloso (1974) e Veloso \& Souza $(1976,1978)$ observaram que as respostas espectrais do café e dos alvos adjacentes foram muito semelhantes nas imagens MSS do Landsat. A melhor resolução radiométrica do sensor TM ( 8 bits ou 256 níveis de cinza) em relação ao MSS (7 bits ou128 níveis de cinza), aliado à melhor resolução espacial das imagens do TM, contribuiu significativamente para melhor definição da resposta espectral, propiciando uma melhor discriminação espectral dos alvos. Vale lembrar que a faixa espectral da banda 4 do TM é similar à da banda 7 do MSS e que a resolução espacial é de 30x30 m para o TM e de 80x80 m para o MSS.

Já a separação das classes café-formação e pastagem nas imagens obtidas nas bandas 3 e 5 (Tabela 2) não foi possível, por causa da similaridade do comportamento espectral entre essas duas classes para todas as datas. Esse fato mostra que, no caso de mapeamento de áreas cafeeiras por meio de imagens de satélites, 
devem-se considerar outros critérios para separar café em formação e pastagem, além do espectral. Um desses critérios é a fotointerpretação na tela do computador, que permite modificar os resultados da classificação digital por meio do conhecimento do fotointérprete, tal como a forma geométrica dos talhões de café, uma vez que a pastagem geralmente não apresenta forma definida (Rudorff et al., 2003). Tardin et al. (1992) afirmaram que no período seco a pastagem, em geral, não apresentou confusão espectral com café, mas, depen- dendo do vigor da pastagem e do café-formação, a separação espectral entre estas classes não foi possível. A classe mata apresentou um comportamento espectral distinto das demais classes nas bandas 3 e 5 em todas as datas.

A data de aquisição da imagem de 3 de setembro 1999 correspondeu ao período mais seco, em relação às outras duas imagens deste mesmo ano (Tabela 2). Esse fato pode ser observado pela maior contribuição do componente solo em relação ao componente vegetação, nas

Tabela 2. Valores médios de reflectância nas bandas 3, 4 e 5 em 1999(1).

\begin{tabular}{|c|c|c|c|}
\hline \multirow[t]{2}{*}{ Classe de uso do solo } & \multicolumn{3}{|c|}{ Valores médios de reflectância (\%) } \\
\hline & Banda 3 & Banda 4 & Banda 5 \\
\hline & & $10 / 8 / 1999$ & \\
\hline Mata & $21,66 \mathrm{a}$ & $42,30 \mathrm{a}$ & $21,69 a$ \\
\hline Café-produção & $28,97 b$ & $54,83 b$ & $35,31 \mathrm{~b}$ \\
\hline Pastagem & $41,12 \mathrm{c}$ & $44,48 \mathrm{a}$ & $53,51 \mathrm{c}$ \\
\hline Café-formação & $43,86 \mathrm{c}$ & $52,43 \mathrm{~b}$ & $48,15 \mathrm{c}$ \\
\hline & & $3 / 9 / 1999$ & \\
\hline Mata & $26,49 \mathrm{a}$ & $34,12 \mathrm{a}$ & $30,52 \mathrm{a}$ \\
\hline Café-produção & $38,69 \mathrm{~b}$ & $42,29 \mathrm{c}$ & $48,64 b$ \\
\hline Pastagem & $53,39 \mathrm{c}$ & $38,11 \mathrm{~b}$ & $65,28 \mathrm{c}$ \\
\hline Café-formação & $55,05 \mathrm{c}$ & $42,19 \mathrm{c}$ & $62,63 \mathrm{c}$ \\
\hline & & $27 / 9 / 1999$ & \\
\hline Mata & $23,37 \mathrm{a}$ & $44,69 \mathrm{a}$ & $29,35 \mathrm{a}$ \\
\hline Café-produção & $33,35 b$ & $49,81 b$ & $49,28 b$ \\
\hline Pastagem & $41,77 \mathrm{c}$ & $45,14 \mathrm{a}$ & $61,82 \mathrm{c}$ \\
\hline Café-formação & $44,92 \mathrm{c}$ & $49,73 b$ & $61,60 \mathrm{c}$ \\
\hline
\end{tabular}

${ }^{(1)}$ Para cada banda e data, médias seguidas de letras iguais não diferem entre si pelo teste Tukey a 5\% de probabilidade.

Tabela 3. Valores médios de reflectância nas bandas 3, 4 e 5, em $2001^{(1)}$.

\begin{tabular}{|c|c|c|c|}
\hline \multirow[t]{2}{*}{ Classe de uso do solo } & \multicolumn{3}{|c|}{ Valores médios de reflectância (\%) } \\
\hline & Banda 3 & Banda 4 & Banda 5 \\
\hline & & $17 / 4 / 2001$ & \\
\hline Mata & $11,17 \mathrm{a}$ & $32,83 a$ & $18,60 \mathrm{a}$ \\
\hline Café-produção & $14,78 b$ & $43,10 b$ & $26,57 b$ \\
\hline Pastagem & $19,00 \mathrm{c}$ & $37,86 \mathrm{c}$ & $32,73 \mathrm{c}$ \\
\hline \multirow[t]{2}{*}{ Café-formação } & $19,74 \mathrm{c}$ & $39,86 \mathrm{c}$ & $35,23 \mathrm{c}$ \\
\hline & & $19 / 5 / 2001$ & \\
\hline Mata & $5,59 \mathrm{a}$ & $48,00 \mathrm{a}$ & $43,84 a$ \\
\hline Café-produção & $9,38 b$ & $65,44 b$ & $62,56 b$ \\
\hline Pastagem & $18,56 \mathrm{c}$ & $52,16 a$ & $48,24 a$ \\
\hline \multirow[t]{2}{*}{ Café-formação } & $22,24 d$ & $58,87 \mathrm{c}$ & $55,46 \mathrm{c}$ \\
\hline & & $7 / 8 / 2001$ & \\
\hline Mata & $16,45 a$ & $43,58 \mathrm{a}$ & $22,21 \mathrm{a}$ \\
\hline Café-produção & $20,50 b$ & $61,83 b$ & $33,64 b$ \\
\hline Café-formação & & $1 \% / 11 / 2001$ & \\
\hline Mata & $15,80 \mathrm{a}$ & $47,23 \mathrm{a}$ & $26,66 a$ \\
\hline Café-produção & $19,99 b$ & $61,84 b$ & $38,51 b$ \\
\hline Pastagem & $23,68 b c$ & $57,46 b$ & $41,24 b c$ \\
\hline Café-formação & $26,58 \mathrm{c}$ & $57,22 b$ & $44,97 \mathrm{c}$ \\
\hline
\end{tabular}

(1)Para cada banda e data, médias seguidas de letras iguais não diferem entre si pelo teste Tukey a 5\% de probabilidade. 
respostas espectrais do café-formação e da pastagem, cujos valores de reflectância na banda 3 são maiores quando comparados com os das demais datas, o que concorda com Tardin et al. (1992). A classe mata, no entanto, foi menos afetada do que a pastagem e o caféformação, o que pode ser atribuído à maior quantidade de folhas verdes, responsáveis pela absorção da radiação incidente com conseqüente diminuição de radiação refletida. Esse fato pode ser notado também ao analisarem os valores de reflectância na banda 4, em relação às demais datas.

Os resultados da Tabela 3 são semelhantes aos obtidos em 1999 (Tabela 2) em relação às datas de 19 de maio e 7 de agosto, em que para a banda 4 as classes café-formação e café-produção diferiram das classes mata e pastagem conforme observado por Tardin et al. (1992). Esse resultado confirma a importância da banda 4 para diferenciar café de mata e de pastagem, nessa época do ano. Já nas datas de 17 de abril e 1 o de novembro de 2001, o café-formação não diferiu da classe pastagem na banda 4. Com relação à data de 17 de abril, observou-se que a resposta espectral na banda 4 , em relação à classe café-produção, foi a menor de todas quando comparada com as demais datas. Esse fato pode ser atribuído, em grande parte, à derriça de folhas durante a colheita, uma vez que nessa data $60 \%$ das lavouras de café do município já haviam sido colhidas. Nessa data, o café-produção diferiu de todas as classes, para todas as bandas, ao passo que o café-formação apresentou resposta espectral similar à classe pastagem.

Em 19 de maio, o café-produção teve resposta espectral diferente do café-formação nas bandas 3, 4 e 5 , e em nenhuma destas bandas o café teve resposta similar às classes mata e pastagem. Em 1o de novembro, as classes café-formação e café-produção apresentaram respostas espectrais semelhantes à classe pastagem, em pelo menos uma das imagens das bandas 3 , 4 e 5 . Este resultado sugere que a classe café pode ser melhor discriminada dos alvos pastagem e mata em imagens adquiridas no período mais seco do ano, conforme relata Tardin et al. (1992).

Ao comparar as respostas espectrais das classes café-formação e pastagem nas imagens obtidas nos dois anos, constatou-se que a pastagem foi espectralmente semelhante ao café-formação em 10 de agosto de 1999 e diferente em relação à data de 7 de agosto de 2001. Isto ocorreu porque no ano de 1999 as lavouras de caféformação se encontravam dois anos mais novas do que em 2001, ou seja, as lavouras classificadas em 2001, como café-formação, estavam com idade de três a quatro anos, ao passo que em 1999 essas mesmas lavouras estavam com idade de 1 a 1,5 ano, quando o solo exerce forte influência na resposta espectral da cultura.

Como a melhor discriminação da classe café, em relação às classes de pastagem e mata, foi obtida nas datas de 10 de agosto de 1999 e de 7 de agosto de 2001, fez-se uma análise para verificar a variabilidade da resposta espectral das lavouras de café-produção nessas duas datas, em relação às imagens reflectância das bandas 3, 4 e 5, conforme apresentado nas Figuras 2, 3 e 4, respectivamente. De acordo com essas figuras, houve variação nos valores de reflectância das lavouras de café selecionadas. Essa variação ocorreu tanto entre lavouras quanto de um ano para outro e foi atribuída ao espaçamento, que na região é muito variável, e à idade dos cafezais que variam entre sete e 30 anos.

Nas lavouras plantadas no sistema convencional, de 3 m entre linhas e 1,5 m entre covas, a resposta espectral foi muito influenciada pela componente solo (Figuras 2 e 3), ou seja, lavouras com maiores espaçamentos apresentaram maiores valores de reflectância na banda 3 e menores valores na banda 4, por causa da maior influência do solo na resposta espectral.

Os valores de reflectância das lavouras cafeeiras nas imagens do ano de 1999 foram maiores do que os observados no ano de 2001 (Figura 4). A causa dessa variação pode estar relacionada com o ambiente mais seco, observado nas imagens adquiridas em 1999. Esse fato, aliado à derriça das folhas durante a colheita, propiciou uma menor absorção da radiação eletromagnética e maior contribuição do solo e, consequientemente, aumentou os valores da reflectância dos cafezais na banda 3, em relação à imagem de 7 de agosto de 2001. Além disso, em alguns talhões de café, essa variação foi mais acentuada, conforme nos gráficos das lavouras de números $4,5,6,12,16,27$ e 28. Nessas lavouras, observou-se em campo que a colheita foi mais tardia e, conseqüentemente, o efeito da estiagem no período seco foi mais acentuado.

No ano de 2001, as variações na banda 4 foram opostas àquelas observadas na banda 3 , ou seja, de um modo geral, as lavouras apresentaram maiores reflectâncias no ano de 2001, exceto para a lavoura 30, com reflectância menor, comparada ao ano de 1999 (Figura 3). Como os maiores valores de reflectância na banda 4 estão relacionados com a quantidade de fitomassa do dossel do cafeeiro, pode-se afirmar que nesse ano 


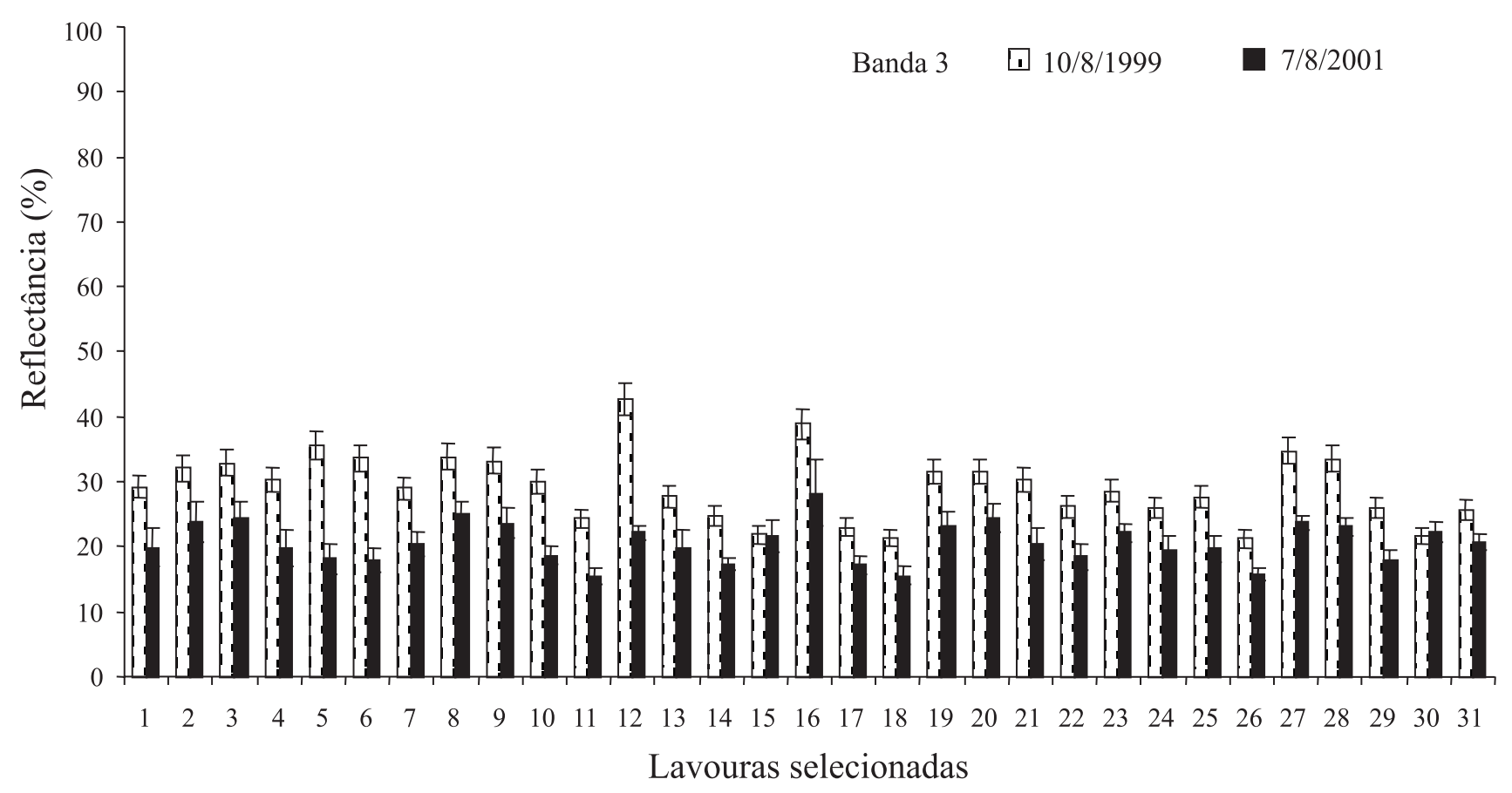

Figura 2. Reflectância em relação às quatro classes de uso do solo por banda nas três datas de 1999. Barra em cada coluna representa o desvio-padrão da média.

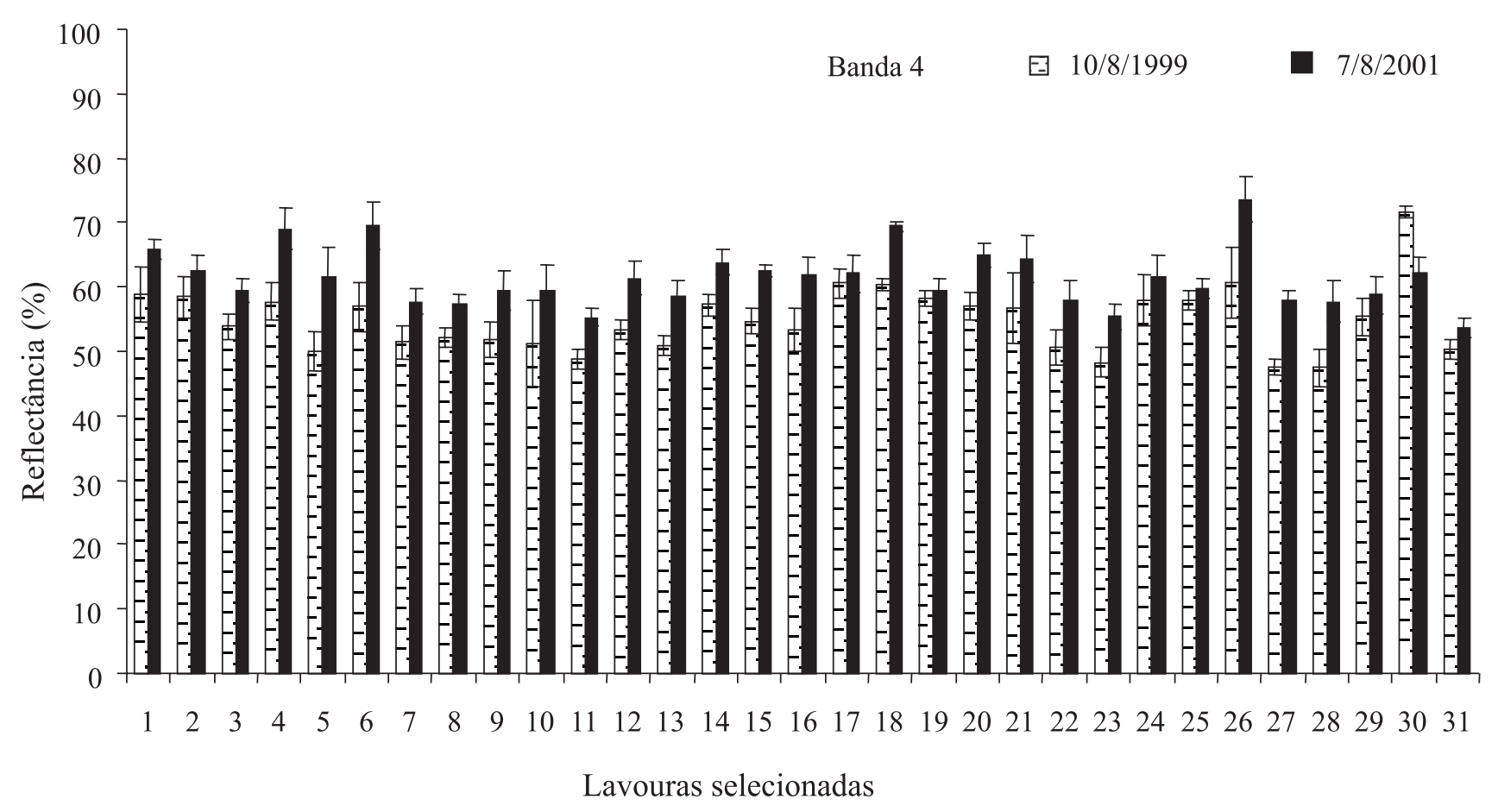

Figura 3. Reflectância em relação às quatro classes de uso do solo por banda nas quatro datas de 2001. Barra em cada coluna representa o desvio-padrão da média. 


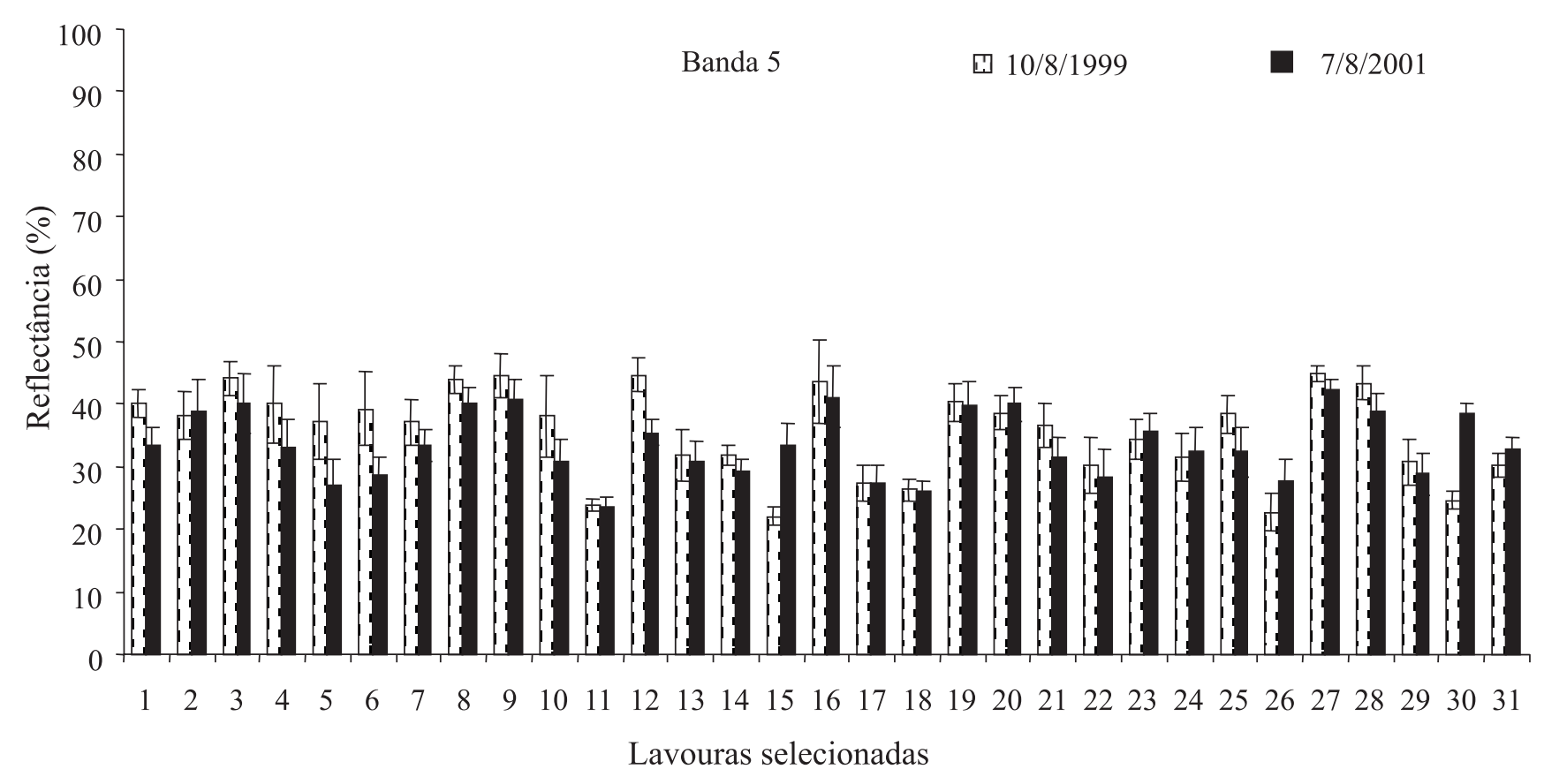

Figura 4. Reflectância na banda 3 em relação às lavouras de café-produção nas datas de 10/8/99 e 7/8/2001. Barra em cada coluna representa o desvio-padrão da média.

agrícola houve menor déficit de água no solo, o que contribuiu para que as lavouras se recuperassem mais rapidamente da derriça de folhas durante a colheita. Uma explicação para o menor valor de reflectância observado na lavoura 30, seria que a mesma foi implantada no sistema superadensado, com espaçamento de $1,5 \mathrm{~m}$ entre linhas e de $0,5 \mathrm{~m}$ entre pés. Quando a lavoura completou cinco anos de idade (ano de 2000), erradicouse uma linha de plantio a cada três linhas. Esse fato diminuiu a quantidade de fitomassa no dossel e, conseqüentemente, diminuiu a reflectância dessa área quando observada na banda 4, na imagem de agosto de 2001.

Com relação à banda 5, nota-se que no ano de 2001 os valores de reflectância foram menores do que aqueles observados no ano de 1999, exceto nas lavouras 15 e 30 (Figura 4). Como a reflectância nessa banda espectral é muito afetada pelo conteúdo de água na planta (Tardin et al., 1992), esse resultado confirma o que foi observado em relação ao comportamento espectral do café no período mais seco de 1999. Com as informações coletadas a campo, foi possível inferir que as menores reflectâncias observadas nas lavouras 15 e 30 estavam relacionadas ao manejo diferenciado aplicado nessas lavouras, ou seja, na lavoura 30 houve redução da fitomassa no dossel por causa do desbaste seletivo; já na lavoura 15 a redução na reflectância relacionou-se com a recepa do cafezal, feita em setembro de 1999. Esse tipo de manejo reduziu também a quantidade de folhas no dossel da cultura e, conseqüentemente, o menor teor de água na planta proporcionou maior reflectância na banda 5 .

\section{Conclusões}

1. O café-formação apresenta semelhança espectral com a classe pastagem nas imagens das bandas 3 e 5 dependendo do estádio de desenvolvimento da lavoura.

2. Lavouras de café-formação e produção não apresentam semelhança de comportamento espectral com pastagem e mata nas imagens da banda 4 .

3. Apesar da perenidade da cultura do café, a melhor época para o mapeamento da lavoura de café pelas imagens multiespectrais de sensores orbitais é nos meses mais secos.

4. O comportamento espectral de lavouras de caféprodução, nas imagens obtidas em agosto de 1999 e 2001, variou tanto entre lavouras quanto de um ano para outro, com maior variação no ano de 2001.

5. Para mapear lavouras de café por meio de imagens orbitais, é fundamental que o resultado da classificação digital seja corrigido por meio da fotointerpretação na tela do computador. 
6. A análise espectral e temporal da reflectância de lavouras de café permite identificar lavouras de café que sofreram redução da fitomassa.

\section{Referências}

EMBRAPA. Centro Nacional de Pesquisas de Solos (Rio de Janeiro). Sistema brasileiro de classificação de solos. Brasília: Embrapa Produção de Informação, 1999. 412p.

HALL, F.G.; STREBEL, D.E.; NICKESON, J.E.; GOETZ, S.J. Radiometric rectification: toward a common radiometric response among multidate, multisensor images. Remote Sensing of Environment, v.35, p.11-27, 1991.

INSTITUTO NACIONAL DE PESQUISAS ESPACIAIS (São José dos Campos, SP). Sistema de Processamento de Informações Georeferenciadas - SPRING 3.5.1: tutoriais. Disponível em: http://www.dpi.inpe.br/spring/portugues/index.html. Acesso em: 23 nov. 2003.

KAUTH, R.J.; THOMAS, G.S. The tasseled cap transformation: a graphic description of the spectral temporal development of agricultural crops as seen by Landsat. In: SYMPOSIUM ON THE MACHINE PROCESSING OF REMOTE SENSED DATA, 1976, Purdue. Proceedings. Purdue: Purdue University, 1976. p.4B414B51.
MELLO, E.V. Cafeicultura no Brasil. In: ZAMBOLIM, L. Tecnologias de produção de café com qualidade. Viçosa: 2001. p.565-646.

PCI REMOTE SENSING CORP. Image works. Ontario: Richmond Hill, 1997. cap. 2.

PINO, F.A. Estimação subjetiva de safras agrícolas. Informações Econômicas, v.31, p.55-58, 2001.

RUDORFF, B.F.T.; AULICINO, L.C.M.; MOREIRA, M.A. Tecnologias geoespaciais no gerenciamento da cultura da maçã. Revista Brasileira de Fruticultura, v.25, p.108-110, 2003.

TARDIN, A.T.; ASSUNÇÃO, G.V.; SOARES, J.V. Análise preliminar de imagens TM visando a discriminação de café, citrus e cana-deaçúcar na região de Furnas-MG. Pesquisa Agropecuária Brasileira, v.27, p.1355-1361, 1992.

VELOSO, M.H. Coffe inventory through orbital imagery. Rio de Janeiro: Instituto Brasileiro do Café, 1974. 20p. (SR-525).

VELOSO, M.H.; SOUZA, D.D. Sistema automático de inventário cafeeiro. Rio de Janeiro: Instituto Nacional do Café, 1976. 8p.

VELOSO, M.H.; SOUZA, D.D. Trabalho experimental de inventariação automática de cafezais utilizando imagens orbitais e o equipamento image-100. Rio de Janeiro: Instituto Brasileiro do Café, 1978. 2p.

ZAMBOLIM, L. Tecnologias de produção de café com qualidade. Viçosa: UFV, 2001. 648p.

Recebido em 29 de julho de 2003 e aprovado em 24 de dezembro de 2003 